\title{
Twenty Years of Deceased Organ Donation in Slovenia: Steps Towards Progress in Quality, Safety, and Effectiveness
}

\author{
Danica Avsec, Jana Simenc* \\ Slovenija-transplant, an Institute of the Republic of Slovenia for Organ and Tissue Transplantation, Ljubljana, Slovenia \\ Email address: \\ danica.avsec@slovenija-transplant.si (D. Avsec), jana.simenc@slovenija-transplant.si (J. Simenc) \\ ${ }^{*}$ Corresponding author
}

\section{To cite this article:}

Danica Avsec, Jana Simenc. Twenty Years of Deceased Organ Donation in Slovenia: Steps Towards Progress in Quality, Safety, and Effectiveness. American Journal of Health Research. Vol. 9, No. 3, 2021, pp. 82-88. doi: 10.11648/j.ajhr.20210903.13

Received: March 29, 2021; Accepted: April 24, 2021; Published: May 21, 2021

\begin{abstract}
The paper describes 20 years of the thriving evolution of the organ donation system in Slovenia. Even before the turn of the century, Slovenia was a pioneering country in South-East Europe in terms of the organizational, legislative, medical, and ethical development of donor and transplantation medicine. Real progress came in the year 2000 when the national donation and transplant competent organization the Slovenija-transplant (ST) institute was established, modern national legislation was introduced, and the country met the demanding entrance requirements to join Eurotransplant (ET), an international foundation for organ and tissue exchanges. Joining the ET led to improvements in numbers of organs procured from deceased donors, allowed better transplant treatment options for Slovenian patients (especially urgent, hyper sensibilized, etc.), reduced patient waiting lists, while the larger 'pool' of patients meant that a suitable match could be found for procured organs. Over the 20 years of deceased donation development, priorities have included assuring the quality, safety, and traceability of human organs, tissues, and cells within an efficient, transparent and ethical transplant system. Great attention has always been placed on frequent, open, transparent, and high-quality communication with the public. Entailing a retrospective study, the article presents analysis of key figures and quality indicators of the Slovenian deceased donation program for the period 2000-2019. Slovenia has stood out for its rate of consent for deceased donation (the 20-year average exceeds $75 \%$ ), been a world leader in the number of heart transplants per million population (at around 11 heart transplants pmp), and has a consistent deceased donor rate (around 20-22 deceased donors pmp). In the challenging pandemic year of 2020, Slovenia once more demonstrated its quality and professionalism. It was one of the countries that best adapted to the crisis. With regular videoconferences on a daily/weekly basis that included professionals and the frequent alteration of safety protocols, the national deceased and transplantation programs were able to remain active and without drops in numbers. The quality of organs and safety for patients was not under threat. Statistics for 2020 show that even more deceased donors and transplantations were performed than in 2019. The article provides an example of good practice of adaptation of the world renowned "Spanish donation model" to suit a specific national context. The findings are useful and transferable to clinical settings in other smaller countries that still need to establish national organ and tissue donation programs. Unfortunately, in many countries around the world (even in Europe), transplant treatment is neither available nor accessible to many patients in need.
\end{abstract}

Keywords: Deceased Organ Donation, Organizational System, National Competent Authority, Quality

\section{Introduction}

Slovenia was a pioneer in South-East (SE) Europe with respect to the development of donor and transplant medicine. The history of transplant activities dates all the way back to the 1970s when the first kidney transplant from a living donor was performed. The first Transplant Law, which emerged in 1985 when still part of the former Yugoslavia, allowed the further development of a deceased donation program. At the transplant center located in the University Medical center (UMC) of Ljubljana, the first kidney from a deceased donor was transplanted in 1986, the first pancreas and heart in 1990, 
along with the first liver in 1995 and lungs in 2003.

Before 1998, donations and transplantations of solid organs were only performed sporadically. Between 1970 and 1990, transplants of kidneys from living related donors were the most active program. A national transplant network and donation and transplantation program with an associated central transplant organization still had to be established. In a relatively small country with a population of around 2 million, for many years the biggest problem was ensuring the compatibility of kidney donors and recipients. In the period 1970-1998, HLA tissue compatibility was achieved in $20 \%$ $35 \%$ of cases. Another problem concerned assuring a suitable organ match for urgent or highly sensibilized patients. There were many structural obstacles in the area of deceased donation, among others a lack of national donation protocols, qualified transplant coordinators, and ICU professionals, especially for donors detection and for brain death confirmation [1].

The need for assuring better transplant treatment options for Slovenian patients, urgent access to a bigger 'donor pool', the improved professionalism of the processes, adequate capacity management, sufficient public trust, voluntary organ donations, regulatory control and a suitable normative environment in harmony with the international directives on human organs, tissues, and cells led to intensive work on setting up a national transplant system.

There is no single or standard way to successfully develop a national system of organ donation and transplantation. A systematic approach to ensuring a comprehensively organized, connected, and well-managed donation and transplant network was developed in Slovenia under the leadership of the Slovenija-transplant (ST) institute. Priorities included assuring the quality, safety, and traceability of human organs, tissues, and cells, and educating professionals and the general public as part of an efficient, transparent, and ethical transplant system.

\section{Development of an Exemplary National Donation Framework}

\subsection{Achieving Progress with a Systematic Approach}

After years of hard effort and the preparation of all necessary quality and organizational procedures, in 1998 the national transplant network was finally in operation. Assuring a central transplant coordination office with 24-hour availability was a vital step in the decisive organizational and legislative progress made in the year 2000 .

\subsubsection{Establishment of the National Competent Institution}

A key step in developing a national transplant program was the establishment of a single professional body responsible for connecting institutions and managing the complex processes and multidisciplinary teams involved in every transplantation treatment. The public institute ST became the central transplant organization linking all institutions and hospitals within the national transplant network and cooperating with
ET, and since 2015 has been operating as the nationally competent authority [1-3]. ST is responsible for the development, management and monitoring of the organ and tissue donation program, the procurement and allocation of organs and tissue, education, public awareness, research, and innovation in the field.

\subsubsection{Development of the Legislative Framework}

The first Slovenian opt-in law on the transplanting of organs and tissues came into force in 2000. In 2015, amendments were introduced to synchronize the national law with the European organ directives concerning standards of quality and safety standards in tissues and cells 2015/566/EU [4], standards for human organs for transplantation 2010/53/EU [5] and on procedures for organ exchange between European states 2012/25/EU [6]. Today, Slovenian law provides a mixed legislative framework (the public has the right to both opt-in or opt-out), anonymity between donor and recipient, and equal access to treatment. Without consent (the known will of the deceased or expressed postmortem consent of the family), deceased donation is not permitted [7].

\subsubsection{Joining Eurotransplant}

After years of preparing to meet the demanding entry requirements, in 2000 Slovenia was the first country in the SE Europe region to join ET, thereby becoming its fifth member country. This accession to an international foundation for organ and tissue exchange helped to significantly improve the national donor and transplant programs. A direct positive impact was seen in the considerable rise in national donation rates, and optimizations of programs for kidney, heart, and liver transplantation (Table 1).

After joining ET, the number of kidney transplants from deceased donors rose 2.8-fold per year compared to the previous 14 years [8]. Waiting lists were appreciably reduced and combined transplantations were introduced. The international exchange of organs has also helped in ensuring that a proper match can be found and thereby the better utilization of procured organs procured in Slovenia. According to ST's statistics, in recent years around 60-70 solid organs have been exchanged between Slovenia and ET in a single year.

\subsection{Priority Actions}

Some elements of the Spanish donation model have importantly guided the evolution of the organizational structure, safety standards, quality control, and traceability system, although the country's public health features and knowledge have always been acknowledged. The WHO's critical donor pathway for deceased donation - The Madrid resolution on organ donation and transplantation of 2010 [9] assisted in defining the steps in the donation process: donor identification, brain death determination, donor screening for organ acceptability, donor management, a family approach, and authorization or consent for organ donation [10]. With a view to ensuring an exemplary national system, the leading institute ST established the following actions as a priority. 
Table 1. Number of transplanted solid organs of deceased donors in Slovenia between 1970 and 2019.

\begin{tabular}{|c|c|c|c|c|c|c|}
\hline Year & Kidney & Heart & Liver & Lungs & Pancreas & Total \\
\hline $1970-1985$ & 1 & & & & & 1 \\
\hline 1986-1989 & 55 & & & & & 55 \\
\hline 1990 & 17 & 1 & & & 1 & 19 \\
\hline 1991-1992 & 31 & & & & & 31 \\
\hline 1993 & 4 & 1 & & & & 5 \\
\hline 1994 & 14 & 2 & & & & 16 \\
\hline 1995 & 10 & 3 & 1 & & & 14 \\
\hline 1996 & 6 & 2 & & & & 8 \\
\hline 1997 & 19 & 6 & & 1 & & 26 \\
\hline 1998 NTN & 46 & 4 & 4 & & & 54 \\
\hline 1999 & 37 & 7 & 9 & 3 & & 56 \\
\hline 2000 ET & 44 & 7 & 10 & 1 & & 62 \\
\hline 2001 & 47 & 4 & 9 & 1 & & 61 \\
\hline 2002 & 55 & 3 & 11 & & & 69 \\
\hline 2003 & 43 & 3 & 9 & 2 & & 57 \\
\hline 2004 & 55 & 3 & 15 & & & 73 \\
\hline 2005 & 28 & 5 & 13 & 2 & & 48 \\
\hline 2006 & 48 & 8 & 8 & 2 & & 66 \\
\hline 2007 & 30 & 11 & 10 & 1 & & 52 \\
\hline 2008 & 52 & 6 & 22 & 4 & & 84 \\
\hline 2009 & 43 & 18 & 18 & 2 & 2 & 83 \\
\hline 2010 & 61 & 19 & 23 & 3 & 1 & 107 \\
\hline 2011 & 46 & 14 & 20 & 7 & 1 & 88 \\
\hline 2012 & 62 & 29 & 27 & 2 & & 120 \\
\hline 2013 & 60 & 30 & 21 & 8 & 4 & 123 \\
\hline 2014 & 55 & 33 & 31 & 3 & & 122 \\
\hline 2015 & 64 & 24 & 24 & 7 & 5 & 124 \\
\hline 2016 & 44 & 31 & 27 & 10 & 5 & 117 \\
\hline 2017 & 46 & 24 & 23 & 8 & & 101 \\
\hline 2018 & 54 & 23 & 27 & 7 & 3 & 114 \\
\hline 2019 & 38 & 22 & 24 & $11 *$ & 1 & 96 \\
\hline Total & 1,215 & 343 & 386 & 85 & 23 & 2,052 \\
\hline
\end{tabular}

* In 2019, UMC Ljubljana restarted the lung transplant program. Before 2019, the majority of such transplants were performed in cooperation with UMC Vienna (Austria). Source: Slovenija-transplant

\subsubsection{The Education of Donation Professionals}

ST also operates as a national educational center for donation medicine and has been paying considerable attention to organizing frequent trainings on organ donation procedures and communication. Since 2001, regular workshops for professionals on the family interview (bringing bad news and asking for an organ donation) have been held. The workshops were based on the European Donor Hospital Education Program model (EDHEP) and later adapted to local needs and recent psychological findings. Over the last 20 years, 59 workshops with 839 participants have been organized. A systematic educational program in Slovenia's donor hospitals on organ donation after brain death started early in 2002 and a normative manual on donor program procedures and national protocols was published in 2003 [11]. In 2008, internationally recognized basic training seminars of the European Training Program on Organ Donation (ETPOD) were introduced. Since 2012, the 3-day intensive course Transplant Procurement Management has been held once a year in cooperation with Spain's Donation and Transplantation Institute. Parallel to this, over the years conferences on specific new methods, trends in donation medicine (especially donor detection, donor evaluation, extended-criteria donors) or workshops on brain death diagnostics have been organized. Short lectures on organ donation and transplantation are part of the regular curriculum at the country's medical faculties and faculties of health sciences. An indirect quality indicator of the successful education of professionals (and an educated general public) is the high consent rate for donation (Table 2).

Table 2. The constantly high consent rate for donation between 2000 and 2019, at an average exceeding $75 \%$.

\begin{tabular}{ll}
\hline Year & \% consent rate \\
\hline 2000 & 63 \\
2001 & 64 \\
2002 & 80 \\
2003 & 78 \\
2004 & 77 \\
2005 & 70 \\
2006 & 81 \\
2007 & 67 \\
2008 & 80 \\
2009 & 85 \\
2010 & 80 \\
2011 & 86 \\
2012 & 69 \\
2013 & 69 \\
2014 & 80 \\
2015 & 81 \\
2016 & 76 \\
2017 & 83 \\
2018 & 66 \\
2019 & 77 \\
\hline
\end{tabular}

Source: Slovenija-transplant

\subsubsection{Appointments and Clearly Defined Roles of Transplant Coordinators}

To ensure the solid work flow of many professionals, ST developed a detailed pyramid of responsibilities and duties of hospital, central transplant coordinators (CTCs), and mentors (respecting Directive 53/2010/EU, [4]). These CTCs operate within the national central office of ST, manage all donations and synchronize organ and tissue exchanges within ET. The availability of the CTCs is assured 24/7. An experienced physician/mentor coordinator offers advisory medical support to the CTCs in the process of evaluating donors and complex cases of extended-criteria donors. The quality system for transplant coordinators assures high professional standards. Eleven donor hospitals, general hospitals with ICU units that participate in the national donor network, have appointed an in-house coordinator. The hospital coordinator is a physician responsible for identifying potential deceased donors, coordinating, and supporting all steps in the donation process, reporting to the CTC and increasing the professionalism, safety, quality, and effectiveness of the donation program in the local donor hospital.

For years, ST has been helping to improve knowledge and the professionalism of the education of transplant coordinators on the European level. Transplant coordinators, mentors, and authorized doctors for the donor program in Slovenia must obtain a European certification as a transplant coordinator within the framework of UEMS Surgery. 


\subsubsection{Management of Donors of Suboptimal Quality}

After Slovenia joined ET, adequate protocols, the intensive education of healthcare professionals and appointments of motivated in-house coordinators in the national transplant network, the number of deceased donors and procured organs gradually started to grow (Table 3 ).

Table 3. Number of organs procured from Slovenian deceased donors between 2000 and 2019.

\begin{tabular}{lllllll}
\hline & Kidney & Heart & Liver & $\begin{array}{l}\text { Lungs (both } \\
\text { lobes) }\end{array}$ & Pancreas & Total \\
\hline 2000 & 43 & 14 & 17 & 4 & 13 & 91 \\
2001 & 44 & 19 & 19 & 7 & 6 & 95 \\
2002 & 66 & 28 & 22 & 11.5 & 11 & 138.5 \\
2003 & 56 & 15 & 21 & 8 & 15 & 115 \\
2004 & 70 & 12 & 25 & 3.5 & 6 & 116.5 \\
2005 & 39 & 13 & 16 & 9 & 8 & 85 \\
2006 & 59 & 16 & 21 & 7.5 & 6 & 109.5 \\
2007 & 46 & 12 & 19 & 7 & 3 & 87 \\
2008 & 71 & 11 & 31 & 9 & 2 & 124 \\
2009 & 65 & 9 & 26 & 4 & 6 & 110 \\
2010 & 80 & 20 & 37 & 13 & 8 & 158 \\
2011 & 58 & 14 & 24 & 4 & 5 & 105 \\
2012 & 89 & 25 & 39 & 8 & 5 & 166 \\
2013 & 86 & 26 & 39 & 19 & 8 & 178 \\
2014 & 80 & 16 & 38 & 11 & 2 & 147 \\
2015 & 92 & 20 & 46 & 6 & 6 & 170 \\
2016 & 68 & 13 & 39 & 13.5 & 2 & 135.5 \\
2017 & 68 & 19 & 40 & 15 & 4 & 146 \\
2018 & 79 & 17 & 34 & 9 & 3 & 142 \\
2019 & 75 & 15 & 31 & 11 & 0 & 132 \\
Total & 1,334 & 334 & 584 & 180 & 119 & 2,551 \\
\hline
\end{tabular}

Source: Slovenija-transplant

Soon, one of the big challenges became the permanent increase in the age of deceased donors. The average age of DBD donors between 2000 and 2010 was 42, whereas between 2010 and 2019 it had risen to 61 . The average donor's age increased by over 10 years in a 10-year period (Figure 1).

As the age of a donor goes up, the chances of medical complexities after an organ donation also go up. This situation means that the majority of deceased donors are of "suboptimal quality" (Figure 2). Extended (expanded) criteria for the procurement and allocation of human organs have become a growing trend in Slovenia, like in many other developed countries.

\subsubsection{Implementation of the Quality Assurance Program}

The rise in numbers and complexity of deceased donors called for further actions to ensure optimization. An important step in upgrading the DBD donation program came in 2011 with implementation of the Quality Assurance Program (QAP). Using selected indicators, the QAP offers the possibility to detect losses in donor detection (comorbidities), weaknesses in donor evaluation (insufficient donor management or the exclusion of donors with extended criteria) and/or the unrecognized role of the transplant coordinator in donor hospitals.

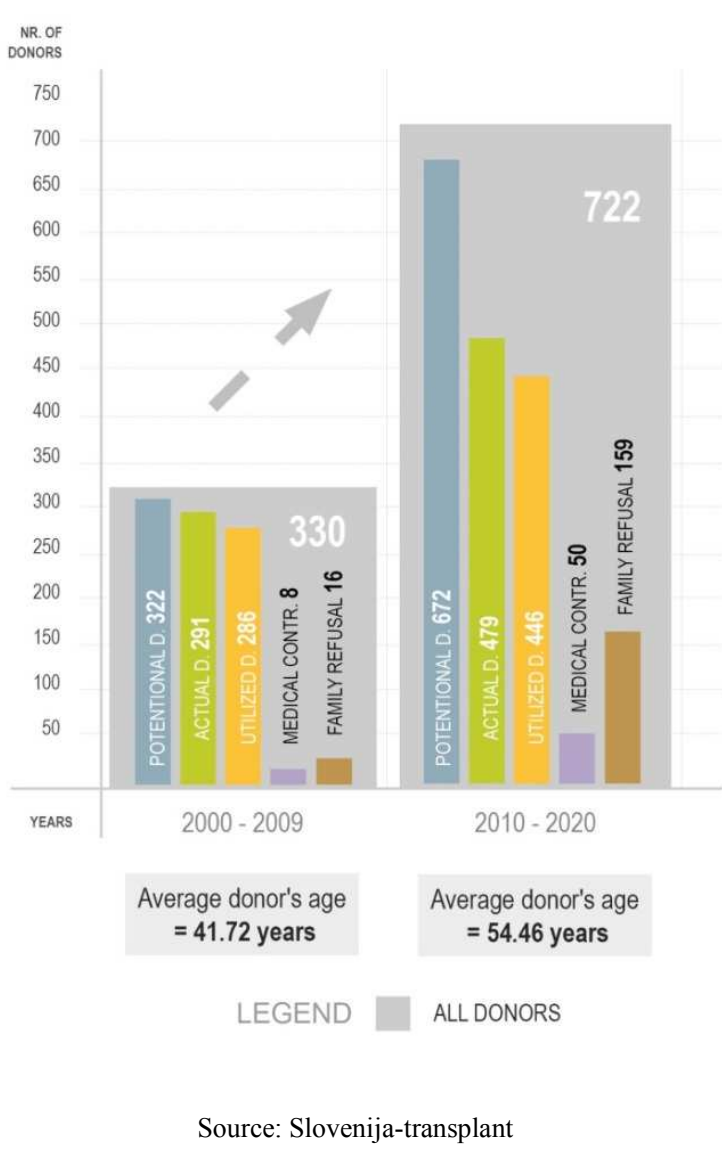

Figure 1. Permanent increase in the average age of deceased donors.

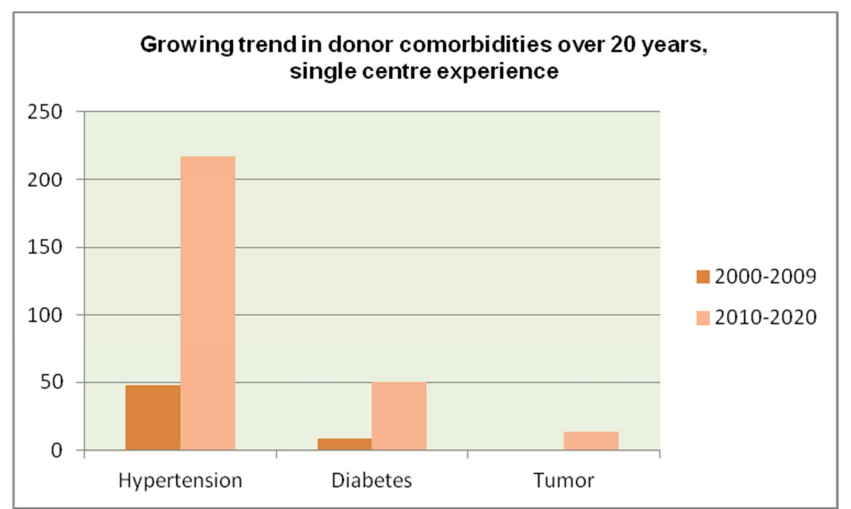

Figure 2. The share of deceased donors with comorbidities has grown significantly in the last 20 years. Selected types of comorbidities (hypertension, diabetes, tumor) are presented. 20 years ago, tumor was an absolute contraindication - due to primary diagnoses, patients were not considered as potential donors. Cases of border/marginal/non-standard/non-ideal or suboptimal quality with medical complexities are still on the rise. With adaptation to the ageing society and advances in donor medicine, the criteria for the suitability of deceased donors are being adequately reassessed and adopted. (Source: Slovenija-transplant).

The QAP's introduction has contributed significantly to improved donor rates (Table 4) and to paradigmatic shifts in the processes of donor evaluation and donor detection. With adequate donor management many malignancies, viral, bacterial, and fungal infections have become a relative contraindication. To assure the highest quality and safety for organ recipients, an 
innovative consultation pyramid for donor and organ evaluation was introduced in the national organizational scheme. Donor detection is the responsibility of both ICU physicians and the physicians at the hospital units where possible donors are being treated. Complex cases of suboptimal deceased donors are evaluated by the professional support of 'mentors' and/or experienced physicians authorized for the donor program. The cooperation of transplant coordinators is also needed during interventions for successful evaluation.

Another reason for implementing the QAP was to create a more cohesive professional donor community and better cooperation with transplant coordinators, directors, and ICU physicians in the donor hospitals around Slovenia. Data analysis and yearly international and external revisions served as a basis for personal meetings of the ST-responsible physician with the hospital management and local professional donation team. The aim of these meetings has always been to come up with an individually tailored solution for professional and quality advances in donation procedures. In 2012, after 1 year of implementing the QAP in all donor hospitals around Slovenia, the detection of potential brain death donors had increased by $77 \%$ (compared to the results for 2011); the rate of actual brain death donors had risen by $52 \%$.

Table 4. Number of utilized deceased donors (DD) and number of utilized deceased donors per million population (DD/PMP) in Slovenia between 2000 and 2019.

\begin{tabular}{lll}
\hline Year & Number of DD & Number of DD/PMP \\
\hline 2000 & 22 & 11.1 \\
2001 & 23 & 11.6 \\
2002 & 35 & 17.6 \\
2003 & 28 & 14 \\
2004 & 36 & 18 \\
2005 & 21 & 10.5 \\
2006 & 30 & 15 \\
2007 & 22 & 10.9 \\
2008 & 36 & 17.8 \\
2009 & 33 & 16.2 \\
2010 & 40 & 19.5 \\
2011 QAP & 31 & 15.1 \\
2012 & 46 & 22.4 \\
2013 & 45 & 21.9 \\
2014 & 43 & 20.9 \\
2015 & 53 & 25.7 \\
2016 & 41 & 19.9 \\
2017 & 39 & 18.9 \\
2018 & 40 & 19.4 \\
2019 & 38 & 18.3 \\
\hline
\end{tabular}

Source: http://statistics.eurotransplant.org/

Through regular meetings, the professionalism, motivation, and cohesiveness of the Slovenian professional community improved. The QAP offers the possibility for more targeted and quicker improvements in the donor program, especially in the (proactive) detection of eligible deceased donors, improved detection and management of suboptimal donors, and achieving greater donor potential in the donor centers around Slovenia.

\subsection{Future Orientations: DCD}

For the last 20 years, the confirmation of brain death has been the dominant criterion for organ recovery in Slovenia. The current national law (2015) allows for donation after circulatory death. Before implementing the DCD program in hospitals, clear and ethically sound national bylaws must be established. In 2013, a qualitative research study on the medical and ethical aspects of DCD among the key transplant professionals in Slovenia was performed [12]. The results showed the participants expressed general support for the introduction of controlled DCD protocols in Slovenia, yet they also shared several professional and ethical concerns. They suggested intensive educational and awareness-raising activities, changes to the organizational donation scheme as well as the development of elaborated, clear, and consensual DCD medical and legal protocols. The participants also agreed, prior to the introduction of DBD, that the full potential of the DBD program must be realized.

The practice of DCD has been expanding around Europe and the world since 2000 [13]. Although the legal frameworks and procedures applied vary, years of experience from the international transplant community show good post-transplant results. The organ quality from DCD donors is comparable to that of DBD donors [14]. A short-term goal of ST is to introduce a controlled DCD protocol into the national deceased donation program. A special working group is resolving obstacles that have emerged in the research, DCD procedures have been integrated into educational courses for health professionals, and a donor hospital has been chosen as a pilot institution. In parallel, attention is put on the introduction of ICOD program, an Intensive care to facilitate organ donation in patients with futile treatment prognosis.

\section{Conclusions}

Slovenia is an example of good practice showing how medically complex and organizational demanding donation and transplant programs can operate efficiently and ethically in a relatively small country (with 1 transplant center and 11 donor hospitals). With ST institute, the country has a central transplant organization. The Institute has developed an exemplary national system, an efficient organizational scheme with a clear division of professionals' tasks and responsibilities during the organ procurement. Integrated quality and monitoring systems ensure high quality and safety standards for both donors and recipients. An adequate legislative and ethical framework, comprehensive educational programs, continuous quality control of the deceased donor program, cooperation in international projects, and a strategic interdisciplinary approach to communication with the public have all constituted the path to success. ST has always shared its knowledge in an international context, contributed to many crucial EU professional documents, and offered advisory support to less developed countries, especially in the SE Europe region.

In many parameters, Slovenia ranks highly alongside the 
most developed countries in Europe and the world [15]. Updated and comparable world data are publicly available from the International Registry in Organ Donation and Transplantation (www.irodat.org). Every year, about 115 solid organs (livers: about 25 or 12 pmp; hearts: 24 or 12 pmp; kidneys: 46 or 22 pmp; lungs: 16 or 7,6 pmp; pancreas: 2 or 1 pmp) and about 85 corneas are transplanted. The country is world leader in the number of heart transplants performed per million inhabitants (about $12 \mathrm{pmp}$ ). Paying attention to the quality of the transplanted organs, parameters for graft and patients' survival rate after the transplanting of solid organs are all excellent and exceed the average in the ET region. The numbers of actual deceased donors pmp (about 22) along with the admirable family consent rate $(70 \%-85 \%)$ demonstrate the achievements of the donation programs and the high public trust in both health institutions and the donation system.

In 2020, a year marked by the Covid-19 pandemic, the cohesive Slovenian transplant community managed to successfully adapt to the changed reality and difficult working conditions. Obligatory donor and recipient PCR testing and other safety measures were introduced in early February 2020, even before the official announcement of an epidemic in Slovenia. A positive test has been an absolute contraindication for donation [16]. The results of the professionally appropriate, brisk, and regular adjustments to the guidelines for the donation and transplantation programs, the dedicated health professionals and continuous flow of information among professionals and with the public were reflected in the numbers of deceased donors and transplantations being higher than in 2019 [17, 18].

There is a constant challenge today to combine the rigid bureaucracy and ever evolving aspects of donor and transplantation activity. Future priority actions include the development of a DCD program, targeted improvements in detecting donors in neurological hospital units, and better characterization of extended-criteria donor processes without endangering the high quality of the organs for transplantation. More research attention is to be paid to improving the biovigilance and measures for reducing the possible transmission of hidden malignant or infectious diseases from donor to recipient. It is expected these will contribute to higher donation rates and advanced quality and safety in the donation program. Such initiatives should bring Slovenia closer to making it self-sufficient.

A further priority is to position deceased organ donation as a standard part of end-of-life care in the healthcare system. Several technical improvements and updated contents in the IT systems and registries for organ, tissues, and cells are required. In cooperation with ET, we shall continue developing ethical and professional strategies for the optimal exchange and use of procured organs and tissues.

Creating and sustaining a high level of public trust and voluntary involvement in organ and tissue donation has always been at the top of ST's agenda. With numerous awareness-raising events and the director of the Institute's continuous well-respected communication with the media, a high level of the general public's trust in the transplant system has been built. Participation in interdisciplinary research projects over the last decade has helped us to gain useful insights into the contemporary social landscape, the public's views on organ donation, and the process underlying the change in behavior to declare oneself as a donor [19].

In today's tormented post-truth era, maintaining public trust through strategic, open, and clear communication with diverse target groups through available channels (including social media) is more important than ever. In the future, the possibilities for changing the policy from mixed to opt-out will be considered. The tradition of non-commercialism and non-profit orientation will be cultivated in the future as well. Only voluntary organ and tissue donations have always been possible in Slovenia, treatment has been available exclusively in the public health institutions, and is covered by the basic health assurance scheme.

\section{Acknowledgements}

The authors wish to thank colleagues at the Institute, especially Andrej Gadzijev and Joze Jakovec for their valuable comments and help with the data collection.

\section{References}

[1] Avsec D, Zupanic Slavec Z (eds). Development of transplant medicine in Slovenia: programmes, guidelines, perspectives. Ljubljana: Slovenija-transplant institute, Celjska Mohorjeva družba; 2016.

[2] Lusicky P, Avsec D. The role of the Institute of the Republic of Slovenia for the transplantation of organs and tissues Slovenia-transplant in the donor program. Zdr. Vest. 2019; 88 (1-2): 3-20. Available at: https://vestnik.szd.si/index.php/ZdravVest/article/view/2833.

[3] Primc D, Racki S, Arnol M, Marinovic M, Fucak-Primc A, Muzur A, Hawlina S \& Markic D. The beginnings of kidney transplantation in South-East Europe. Acta clinica Croatica. 2020; $\quad 59 \quad$ (1): https://doi.org/10.20471/acc.2020.59.01.16.

[4] Commission Directive (EU) 2015/566 implementing Directive 2004/23/EC as regards the procedures for verifying the equivalent standards of quality and safety of imported tissues and cells. Available at: https://eur-lex.europa.eu/legal-content/EN/TXT/?uri=uriserv: OJ.L_.2015.093.01.0056.01.ENG.

[5] Directive 2010/53/EU on standards of quality and safety of human organs intended for transplantation, Available at: https://eur-lex.europa.eu/legal-content/EN/TXT/?uri=LEGISS UM:sp0008.

[6] Directive 2012/25/EU on information procedures for the exchange, between Member States, of human organs intended for transplantation. Available at: https://eur-lex.europa.eu/legal-content/EN/TXT/?uri=CELEX: $32012 \mathrm{~L} 0025$.

[7] Act Regulating the Obtaining and Transplantation of Human Body Parts for the Purposes of Medical Treatment (ZPPDČT), Official Gazette of the Republic of Slovenia, no. 56/2015. Available http://www.pisrs.si/Pis.web/pregledPredpisa?id=ZAKO6624. 
[8] Kandus A, Arnol M, Bren F. A. Renal transplantation in Slovenia after joining Eurotransplant, Nephrology Dialysis Transplantation. 2006; 21 (1): 36-39. Available at: https://doi.org/10.1093/ndt/gfi277.

[9] The Madrid resolution on organ donation and transplantation: National responsibility in meeting the needs of patients, guided by the WHO principles. Transplantation. 2011; 91 (11): 29-31.

[10] Dominquez-Gil B, Delmonico L F (et al). The critical pathway for deceased donation: reportable uniformity in the approach to deceaed donation. Transplant International. 2011; 24: 373-8.

[11] Avsec Letonja D, Voncina J (eds). Transplantation: donation programme. (in Slovene). Ljubljana: Slovenija-transplant, 2003.

[12] Avsec D, Simenc J. Donor programme after circulatory death in Slovenia: Analysis of the views of professional community and future perspectives. Zdrav Vestn. 2020; 89 (5-6): 255-67. Available https://vestnik.szd.si/index.php/ZdravVest/article/view/2974.

[13] Guide to the quality and safety of organs for transplantation. 7th ed. Strasbourg: EDQM, Council of Europe; 2018.

[14] Lomero $\mathrm{M}$ et al. Donation after circulatory death today. An updated overview of the European landscape. Transplant International, 2019. Doi: https://doi.org/10.1111/tri.13506.

[15] Bouwman R et al. Study on the uptake and impact of the EU Action Plan on Organ Donation and Transplantation (2009-2015) in the EU Member States. Luxemburg, European Union, 2017.

[16] Avsec D. Donor and transplantation activity in time of Covid-19 epidemic. Isis, June 2020: 27-28.

[17] Arnol M, Smrkolj T, Avsec D, Gadzijev A, Knezevic I. An increase in kidney transplantation procedures from deceased donors during the Covid-19 epidemic in Slovenia. Transplant International. 7 August 2020, doi https://doi.org/10.1111/tri.13715.

[18] Donation and transplantation activity in Slovenia in 2020: factsheet and highlights. Available at: https://www.slovenija-transplant.si/?action=viewArticle\&artic leId $=40$.

[19] Berzelak N, Avsec D, Kamin T. Reluctance and willingness for organ donation after death among Slovene general population. Slovenian journal of public health. 2019; 58 (4): 155-163. Available at: 